\title{
Leg Weaknesses and Lameness Assessment Methods in Broiler Chickens
}

\author{
Arda Aydin* \\ Department of Agricultural Engineering and Technologies, Faculty of Agriculture, Canakkale Onsekiz Mart University, Turkey.
}

*Corresponding author: Arda Aydin, Department of Agricultural Engineering and Technologies, Faculty of Agriculture, Canakkale Onsekiz Mart University, Turkey.
Received Date: November 23, 2018

Published Date: December 14, 2018

\begin{abstract}
In this study, firstly, a brief evolution of the chickens was mentioned and then 'leg weakness' and what leg weakness means in the broiler sector were investigated. "Leg weakness" is a vague term used to describe properties of infective and non-infective nature that occur in modern, fast-growing broilers. Modern broilers commercially grown are prone to foot problems, including lameness, footpad dermatitis and hock-burn. Lameness is an extensive term used for some damages of broiler chickens with infective and non-infective source. Lameness is a very big problem in the broiler industry. For the United State in 2002, the costs of lameness were predicted to be between $\$ 80$ million and $\$ 120$ million. However, in literature, it has been proven that the lameness strongly correlated with weight, growth rate and activity. The time before the chick reaches, a live weight of $1500 \mathrm{~g}$ was reduced from 120 days to 30 days in 80 years. As results of fast growing, severe problems have been occurred in broiler chickens. For example, the animals with severe problems have a reduced feed efficiency and lower growth. The carcass quality of these animals has also been decreased in value. Additional to the welfare problems that have been caused by leg problems, also financial losses have been occurred for the producers. Therefore, the first purpose of this study is created as to review the leg weaknesses of broilers and provides to readers a brief discussion of the factors influencing this problem. The second purpose of this study is to review the lameness and lameness assessment methods for broilers. Additionally, the advantages and disadvantages of these methods are discussed. At the end of this review, brief conclusions can be found with related reference list.
\end{abstract}

Keywords: Precision livestock farming; Broiler; Lameness; Chicken; Technology; Image analysis; PLF

\section{Introduction}

The poultry industry has grown enormously over its fifty-year history until these days and now more than 20 billion broiler chickens are produced every year. The demand for increased growth rate and production due to the economic benefits of higher body weight has led to the differential growth of body parts like accelerated growth of muscle [1]. However, this growth is not accompanied by the skeletal development. Lame broilers cannot walk easily and unfortunately, they cannot reach the feeder and the drinker when they are hungry or thirsty. Lameness is reducing their life quality. The existence of lameness is strongly correlated with weight and rapid growth of broilers [2]. Furthermore, movement problems may be painful for the broilers. It can decrease the broiler's activity and increase different problems, like hock burns and chest dirtiness [3]. Rapid growth rate accompanied by adequate nutrition, proper management, optimum lighting and temperature, a disease-free environment prevents weakness in broiler chickens. The absence of any of these factors combined with the intrinsic weight bearing characteristics give rise to the different degrees of leg disorders [1]. Leg weakness can be classified as infectious, developmental metabolic and degenerative disorders. Leg weakness leads to high incidence of morbidity than mortality [1]. However, the disabled bird experiences pain, does not reach feed and water and dies due to inanition $[4,5]$. Therefore, the first purpose of this study is created as to review the leg weaknesses of broilers and provides to readers a brief discussion of the factors influencing this problem. Among the factors that cause the leg weakness, include nutritional deficits, mechanically induced trauma, toxins, genetic defects, pathogens infectious diseases, sex, weight and growth rate, age, the efficiency of feed conversion, handling and movement. The second purpose of this study is to review the lameness and lameness assessment methods for broilers. 


\section{Leg weaknesses}

The changes in diet were increased the nutritional and physical density of broilers. Higher nutrient intakes a combination of these two factors has ensured that the growth rate has dramatically raised in broilers [6]. The time before the chick reaches a live weight of $1500 \mathrm{~g}$ was reduced from 16 weeks to 4 weeks in order to utilize this genetic potential for growth are good highly concentrated feed in pellet form and extensive lighting schedules required. Along with a selection for rapid growth to rap to achieve, a high body weight has also been selected for the construction of more breast muscles. This changes the conformation of the chicks, and this can give rise to bone abnormalities [7]. Additional to the welfare problems that are caused by leg problems will also occur a financial loss for the producer. The animals with severe problems have a reduced feed efficiency and lower growth. The carcass quality of these animals will also decrease in value [8].

\section{Occurrence}

Most cases of lameness in broilers due to skeletal abnormalities, but it is hard to describe. Cost and losses thereby accurately bone abnormalities may lead to an increase in the mortality rate, "the cull", the percentage of rejected chicks and the "downgrades from trimming" [1]. Losses by skeletal abnormalities in broilers are significant [9]. In some stables there have up to 90 percent of the birds some degree of lameness in slaughter age [10] and about 30 percent of the birds are simply too severely crippled [11].

\section{Changes in behaviour}

The bulk of the day of a roaster is lying spent. A quarter of this time seem the chickens to sleep and more than half of the time they are just not doing anything. A healthy chicken is on average 76 percent of the time spent lying. This percentage is increased with age, and it is indicated that it is significantly larger with a higher degree of lameness (up to 86 percent).

\section{Types of Defects}

The lameness problem of broilers is not only caused by malformations or infection. Heavy, birds, which have no apparent disease, walk like she is suffering and prefer to stay. That may indicate the pain is related to the body weight and the pressure on the bones and tissues [6].

\section{Bone abnormalities}

Bone abnormalities may be caused in various ways such as nutritional deficits, mechanically induced trauma, toxins, and genetic defects. All these factors play a greater role in the fastgrowing chicken breeds. They need for their rapid growth. More and more specific nutrients they are more susceptible to trauma because their bones are not fully developed. So, bone abnormalities are common in the production of commercial broilers.

\section{Valgus-varus}

Valgus deviation results in a "knock-kneed" appearance. The tars metatarsus deviates laterally when she is placed with the tibiotarsus in a line. It is the most common form of long bone defects, and it is quite serious [9]. This deviation results in a 'bow- legged' appearance. The tars metatarsus differs in now wondering if she is placed with the tibiotarsus on a line. This deviation is less common but leads to severe walking difficulties [9].

\section{Tibia dyschondroplasia (Td)}

TD seems to be a decoupling of growth plate chondrocyte proliferation during endochondral calcification leg extension and the result [9].

\section{Rickets}

This is probably the best-characterized bone disease in poultry. It happens when bone mineralization is reduced. It is commonly caused by a deficiency of calcium and phosphorus or an imbalance between these [9]. 'Rickets' can occur in both fast-and slow-growing chicks, but it is made worse by a greater need for nutrients in the growth.

\section{Femoral head necrosis}

This syndrome, the causes of which are unknown, may affect the entire house. The clearest indicator is the inability of the broilers to stand up. When there is an autopsy is carried out on the birds, it is the end of the femur. The broilers can respond to vitamin D3 in the drinking water, but this method does not work every time [9].

\section{Chondrodystrophie}

Poultry with a shortage of water-soluble vitamins can develop shorter bones with varus abnormalities. If the deficiency is too much, the gastronomies tendon of the supporting can slip cartilage [9].

\section{Contact dermatitis}

Feet burns, lesions that can be summarized under the heading of contact dermatitis have risen in recent decades in broilers. It is believed that contact dermatitis is caused by the effect of ammonium chemical burning of the urea in the litter. There is also evidence that the incidence and severity of contact dermatitis reflects on the quality of the litter and the air, so actually on welfare aspects other than pain [12]. Contact dermatitis is clear due to very long time spent for sitting and bad litter. The time that is spent for sitting and lying by the chicks, increases with the age from 75 percent in the first week to 90 percent at five weeks [5]. Footpad dermatitis is a type of contact dermatitis, which is characterized by lesions on the soles of poultry. In severe cases, there is a swelling and necrotizing tissue occurs or can be observed. This can lead to a problem in the food hygiene because these lesions may be used as entrance road for bacteria. This then leads to a poorer carcass quality [13].

\section{Infectious Diseases}

\section{Pathogens}

The main pathogens that can cause lameness are Reovirus, Mycoplasma sinoviae, Staphylococcus aureus and Retroviruses.

\section{Reovirus}

Avian reoviruses, which causes of viral arthritis / tenosynovitis (inflammation of the tendon sheath), are widespread in the broiler industry. It is suspected that the virus can spread through 'avian egg 
transmission', especially since the virus was found in apparently normal embryos from commercial chickens. The clinical picture is characterized by mild to moderate lameness; swollen 'hocks' met a noticeable increase of fluid in the "hock" joints [14].

\section{Mycoplasma synoviae}

Invisible Mycoplasma Synoviae causes respiratory diseases but can also result in airsacculitis and synovitis in chickens and turkeys. The effects of M. synoviae were first established in the 50s, it was still identified for the organism. Characteristic of M. synoviae is the difference in pathogenicity between different strains. Of these, seemingly cause no trace of disease to those diseases of the respiratory tract and/or synovitis [15].

\section{Retroviruses}

Among the most important retroviruses, include the avian leucosis viruses. They are divided into several subgroups. Avian leucosis virus subgroup J (ALV-J), this is one of the most economically important pathogens in broilers. The nodes consist of myelocytes with characteristic eosinophilic cytoplasmic granules. There may be other types of lesions occur as long sarcoma's abnormal feathers and infiltration of myelocytes in the bones and the periosteum of the sternum and the ribs [16].

\section{Staphylococcus aureus}

Staphylococcus aureus is a major cause of illness in the broiler industry. Infection with S. aureus can cause many different clinical features such as septicemia (prevention of pathogenic microorganisms and their toxins in the blood), bone and joint infections, abscesses and dermatitis. Such diseases bring animal welfare compromised and cause economic losses due to downtime, reduced productivity, and carcass contamination in the slaughterhouse [17].

\section{Mycotoxins}

Mycotoxins are one of the nutritional factors causing skeletal disorders such as Rickets, Articular Gout and Tibia Dyschonroplasia and the list various bone diseases in broilers possibly caused by mycotoxins [1]. Mycotoxins such as aflatoxin, ochratoxin and fusarium toxin lead to rickets due to their toxic effects on liver and kidney, which consequently prevents the conversion of vitamin D3 and its absorption [1].

\section{Lameness}

According to the European Commission report lameness is the main cause of bad welfare in broiler chickens [18]. Lameness is an extensive term used for some damages of broiler chickens with infective and non-infective source [19]. Lameness is also a very big problem in the broiler industry. The financial losses due to lameness in the commercial grown broilers are considerable [20]. For the United State in 2002, the costs of lameness were predicted to be between $\$ 80$ million and $\$ 120$ million [21].

\section{Causes of Lameness}

Among the factors that cause lameness, include infectious diseases, genetics, sex, weight and growth rate, age, the efficiency of feed conversion, nutrition, handling and movement. These factors will be discussed further below. The key factors here of non-infective and non-nutritional bone abnormalities its genetic selection and the management [22].

\section{Weight and growth rate}

The rapidly increasing weight will require more of the immature skeleton and the shape change can alter the forces, which are produced during the run. The high 'Gait Score' in broilers may thus be the consequence of pain, biomechanical problems, or both [23]. [24] investigated the relationship between lameness, weight, growth rate and age. The results indicated that weight and growth rate were important factors for lameness [24].

\section{Gender}

Both sexes have problems of lameness. However, the male chicks encountered more problems than the female, even when the body weight is considered. The 'gait score "of the males was about half a' gait score 'unit higher [25].

\section{Genetics}

There is evidence that there are differences in the occurrence of 'leg weakness' between several commercial breeds that perform the same for the rest [10]. Genetically different genetic experiments have shown that the cause lameness bone abnormalities which possess a certain degree of heritability [26]. It appears that lameness is more common in some breeds than others are. Positive selection against these characteristics, it is therefore possible [26].

\section{Age}

The investigation of [25] found that the ability to walk properly deteriorated with age. At the age of four weeks, the chickens could still run well. Less than 1 percent of these birds had a gait score of 4 or 5 on 6 weeks of age the broilers were significantly worse walking and at 7 weeks they could run worse. The speed at which the deteriorated chicks between 4 and 6 weeks was larger than that between 6 weeks and 7 weeks [25].

\section{Food (Nutrients)}

It has been shown that nutrients are important for the normal skeletal development. A well-balanced diet is essential in broilers to prevent leg disorders. For example, a shortage of water-soluble vitamins, manganese, or zinc may lead to the development of shorter bones with valgus abnormalities. In addition, 'rickets' can be exacerbated by a lack of nutrients in fast-growing chickens [6]. Small shortages of biotin in feeding schedules caused more footpad dermatitis [27].

\section{Composition and feeding schedule}

A reduction of the growth rate by means of the restriction of feed can reduce the occurrence of bone abnormalities, which are not caused by an infection. It could be that food restriction works by slowing the growth rate of the muscle tissue, thereby increasing the growth rate of the bone tissue. [31] Conducted a study to determine whether a manipulation of the feed pattern or early feeding pattern would have effect. Fewer meals per day were associated with a 
lower incidence of TD, less "hock burn, a better gait, lower body weight and better feed conversion. [4] Suggested that this was due to a better-organized feeding pattern, resulting in more activity.

\section{Management}

Management consists of many different factors, such as bedding, ventilation, heating, lighting diagrams, nutrition, occupation, enrichment of the cages. According to management, consultants are deficiencies in these factors, the main cause of the high incidence of foot pad dermatitis. It is advised to producers to increase the ventilation and start relatively early. It is also recommended to use thin layers of litter and sometimes change from straw to wood shavings. It would be easier to scrape the chickens, and it can more easily be kept dry and ventilated [13].

\section{Litter}

When housing poultry litter on the ground is well important. A good litter material can be defined as a material that can absorb and give off a lot of moisture back. In practice, wine wood shavings and straw, the most commonly used materials [30]. It was also reported all that chicks that sit on wood shavings show higher activity than those sitting on straw. This could also be an occasion for less lameness [31].

\section{Conditioning (Heating and Ventilation)}

The high and low temperature is associated with increased incidence of leg disorders. At a low occupancy is apparent that the air has little influence on the chick quality. At a higher occupancy (20 chicks per $\mathrm{m} 2$ ), however, the climate has an influence: the proportion chicks with diseased feet are lower and they are less soiled [30].

\section{Light}

The broiler industry is continuing illumination or nearly continuous illumination ( $23 \mathrm{~h}$ light: $1 \mathrm{~h}$ dark) standard to increase the food intake and growth rate [22]. The light can have an influence on behavior, physiology and well-being in different ways. There are studies that have shown that lameness and growth of chicks is influenced by different light periods [31].

\section{Occupancy}

The use of high occupancy is far-reaching to economically maximum advantage. Use of the surface however, the capacity is limited by the bad effects that this has on the growth and quality. The occupation has a clear influence on the external quality of the chicks. In the lower occupancy of 16 chicks per $\mathrm{m} 2$ is the number of chicks with red heels considerably lower and annotating of the soles is significantly less. Moreover, there are fewer varieties for the chicks less soiled at low stocking densities [30].

\section{Enrichment}

It was proved that birds, which were trained less bone abnormalities exhibited from 33 days [5]. The sober environment can contribute to moving the little chicks. There are different attempts have been made to enrich the surrounding area. Enrichment of the broiler house can contribute to greater activity, and it can improve the bones of chickens, including their welfare [5].

\section{Assessment of lameness}

Traditional methods to determine the gait score as an indicator for lameness include manual scoring of birds' movement and other behaviors in the farm. Nevertheless, it is difficult to score the behaviors of broiler chickens. Compared to traditional methods, fully automated image analysis techniques have many potentials for lameness assessment. Automatic video image technique to analyze the activity as an indicator of lameness in broilers is becoming popular [30] because it is getting cheaper. It is also noncontact method, which allows recording more frequent data during the life span of broiler chickens. There is also no need for huge data storage when data are automatically evaluated in real-time [30]. The measurements can also be performed continuously and automatically throughout the life span of birds with non-invasive and non-intrusive way. It is also do not involve the biosecurity risk of having people visiting different commercial farms to perform visual gait scoring for boiler chickens [31].

\section{Manual assessments (Gait scoring system)}

The first manual assessment technique was developed by [32] to evaluate the gait problem in birds by visually observing and giving some gait scores for each broiler chicken. In this method, a score is assigned ranging from zero (no leg problems) to five (completely paralyzed) according to the criteria as follows. 0 (healthy broiler); 1 (the broiler moves fast, but there is a slight walking deficiency); 2 (the broiler moves fast, but significant walking deficiency is observed); 3 (the broiler moves fast, but there is a significant deficiency); 4 (the broiler cannot move fast and there is a serious difficulty); and 5 (the broiler cannot move anymore).

\section{Bristol scoring system}

The University of Bristol's Gait Scoring Guide is widely used to assess walking ability. This scoring system works on the same principle as the Gait Scoring System. Here, too, each broiler again a score from 0 to 5 according to certain criteria. The score is awarded by experts [32]. Although this method is often used because it is so easy to apply, it is still very subjective. It depends on the expertise and experience of the observer. Other studies showed that the repeatability of the visual gait score is not entirely reliable. From other studies even more important are that only the movement scored with this method, and not the pressure exerted by the chick. It will therefore not give objective information on whether the animal is in pain or not [33].

\section{Automatic Assessment Systems}

\section{Pedobarograph system}

The light intensity will be in proportion to the applied pressure [33]. The gait-analysis was performed using a purpose-built pedobarograph. When pressure is exerted on the surface, the emulsion side of the photographic paper pressed closer against the glass so that the light is distributed. This can be seen on the bottom of the glass. The glass plate and the career were both covered with 
polythene-backed protective sheeting "(Benckhote, Whatman International Ltd) in order to ensure the birds. For a homogeneous surface under the glass is a mirror placed at an angle of 45 degrees. The divided light is reflected by the mirror and filmed with a closedcircuit camera (Panasonic WV-BP3101B0). The video was recorded on a S-VHS recorder (Panasonic AG-7355), and images warden transferred to a Powermac 8100/110 computer with a Scion LG-3 frame grabber card and analyzed using Scion Image (version 1.57) software (Scion Corporation, Maryland, USA). In this study, there were 12 frames per second. Each pixel is given a value between 1 and 254, depending on the brightness of that point. The system can then be calibrated to relate with applied pressure [34].

There were several gait parameters measured and compared between the different groups:

- $\quad$ Speed $(\mathrm{m} / \mathrm{sec})$

- $\quad$ Step frequency (steps/min)

- $\quad$ Step width

- $\quad$ Step length

- $\quad$ Step angle

\section{Video recordings}

In another study, the behavior of broiler chickens related with lameness was investigated by [16]. Comparisons were performed between healthy broilers and lame birds between 39 and 49 days old. Healthy birds spent $76 \%$ of their time as lying and $24 \%$ of their time as standing and/or moving. Lame broilers with gait score 3 spent $86 \%$ of their time as lying in. Lying events were also increased with the age of broilers [16].

\section{Latency to lie test}

In broilers, another method for lameness assessment was described by [35]. The time duration that birds stayed standing in water was measured and the results were checked with traditional results. There was an important $(\mathrm{P}<0.001)$ correlation among the gait scores and LTL of birds. More than 750 birds at the age between 32 and 45 days old were tested in a broiler house. Almost all of the healthy broilers were able to stand for at least 15 minutes and most of the lame broilers sit down in five minutes.

\section{Force plate study of avian gate}

Another method was developed by [36] to define the ground reaction force of birds. The ground reaction force was tested while the broilers walked on the experiment setup. GRF patterns represented important changes during growth. It was concluded that the force plate is an appropriate study tool for recording the ground reaction force patterns of broilers.

\section{Precision livestock farming approaches to detect the lameness of broilers}

Automatic monitoring the activity in broiler chickens is one of the easiest ways to define lameness at broiler houses. A fully automated monitoring system was developed by [37] to measure the broilers activity at different gait scores. The activities were obtained by using an automatic video recording system. Then, the images of the birds with six different lameness level were automatically analyzed by the developed algorithm. The results showed that, there was an important correlation among the lameness obtained by expert and activity recorded by image monitoring tool [37]. It was also detected that there was an important lower activity of high gait score broilers (GS4\&GS5). Therefore, it was concluded that, this technique can be used as indicator of high lameness level (GS4\&GS5) in broiler houses. Another study was performed by [30] to define a new technique to estimate the spatial use of broilers by using image analysis. An important relationship was observed for both experiments among the lameness and the movement recorded by the image monitoring tool. The results also showed that there was a strong relationship between the spatial use of broilers with a certain lameness level and activity. Therefore, it was also concluded that the spatial use of broilers can also be a kind of indicator for activity and criteria for lameness assessment [30].

\section{Conclusion}

As explained in this study, leg weakness includes a wide range of abnormalities due to a multitude of etiological causes. It is definitely affecting the growth and end-weight of broiler chickens consequently causing a huge economic loss to the farmer. As detailed above, the leg weakness of broiler chickens is influenced by many different factors, which needs to be considered when managing broilers. Leg weakness can be prevented by modifying the environment and diet. In addition, growth rates can be reduced by artificial lighting and restricted feeding. However, proper manage mental practices should be adopted [38-51].

\section{Acknowledgment}

None.

\section{Conflict of Interest}

No Conflict of Interest.

\section{References}

1. SD Verma (2006) Mycotoxins affect bone structure and leg weakness. World Poultry 11

2. G Su, P Sørensen, SC Kestin (2000) A note on the effects of perches and litter substrate on leg weakness in broiler chickens. Poultry Science 79(9): 1259-1263.

3. BR Thapa (2004) Detection of avian leukosis virus subgroup $\mathrm{j}$ in chicken flocks from Malaysia and their molecular characterization, Avian Pathol 33(3): 359-63.

4. AJE Webster (1995) A cool eye towards eden. Oxford, Blackwell Science, USA.

5. CA Weeks, SC Kestin (1997) Effect of leg weakness on the behaviour of broilers. Proceedings of the $5^{\text {th }}$ Poultry Welfare Symposium, Wageningen. the Netherlands, p. 117.

6. RJ Julian (1998) Growth problems: ascites and skeletal deformities in broilers. Poultry Science 77(12): 1773-1780.

7. SA Corr, MJ Gentle, CC Mccorquodale, D Bennett (2003) The effect of morphology on walking ability in the modern broiler: a gait analysis study. Animal Welfare 12(2): 159-171.

8. HH Kristensen, GC Perry, NB Prescott, J Ladewig, AK Ersboll et al. (2006) Leg health and performance of broiler chickens reared in different light environments. British Poultry Science. 47(3): 257-263. 
9. ME Cook (2000) Skeletal deformities and their causes: introduction. Poultry Science 79(7): 982-984.

10. SC Kestin, TG Knowles, AE Tinch, NG Gregory (1992) Prevalence of leg weakness in broiler-chickens and its relationship with genotype. Veterinary Record 131(9): 190-194.

11. GS Sanotra, JD Lund, AK Ersboll, JS Petersen, KS Vestergaard (2001) Monitoring leg problems in broilers: a survey of commercial broiler production in Denmark. Worlds Poultry Science Journal 57(1): 55-69.

12. SM Haslam, SN Brown, LJ Wılkıns, SC Kestın, PD Warrıss et al. (2006) Preliminary study to examine the utility of using foot burn or hock burn to assess aspects of housing conditions for broiler chicken. British Poultry Science 47(1): 13-18.

13. C Ekstrand, TE Carpenter, I Andersson, B Algers (1998) Prevalence and control of foot-pad dermatitis in broilers in Sweden. British Poultry Science 39(3): 318-324.

14. AS Dhillon, HL Thacker, AV Dietzel, RW Winterfield (1981) Respiratory cryptosporidiosis in broiler chickens. Avian Diseases 25(3): 747-751.

15. SB Lockaby, FJ Hoerr, LH Lauerman, SH Kleven (1998) Pathogenicity of mycoplasma synoviae in broiler chickens, Veterinary Pathology 35(3): 178-190.

16. CA Weeks, TD Danbury, HC Davies, P Hunt, SC Kestin (2000) The behavior of broiler chickens and its modification by lameness. Appl Animal Behav Sci 67(1-2): 111-125.

17. JJ Mccullagh, PT Mcnamee, JA Smyth, HJ Ball (1998) The use of pulsed field gel electrophoresis to investigate the epidemiology of staphylococcus aureus infection in commercial broiler flocks. Vet Microbiol 63(2-4): 275-281.

18. Scahaw (2000) The welfare of chickens kept for meat production Report of the Scientific Committee on Animal Health and Animal Welfare Brussels, Belgium, European Commission, Health and Consumer Protection Directorate- General.

19. TM Rousing, Bonde, JT Sorensen (2000) Indicators for the assessment of animal welfare in a dairy cattle herd with a cubicle housing system. In Improving Health and Welfare in Animal Production: 37-44.

20. TG Knowles, SC Kestin, SM Haslam, SM Brown, LE (2008) Green Leg disorders in broiler chickens: Prevalence, risk factors and prevention.

21. TW Sullivan (1994) Skeletal problems in poultry: Estimated annual cost and descriptions. Poultry Sci 73(6): 879-882.

22. RH Bradshaw, RD Kırkden, DM Broom (2002) A review of the aetiology and pathology of leg weakness in broilers in relation to welfare. Avian and Poultry Biology Reviews 13(2): 45-103.

23. SC Kestin, S Gordon, G Su, P Sorensen (2001) Relationships in broiler chickens between lameness, liveweight, growth rate and age. Veterinary Record 148(7): 195-197.

24. P Sorensen, G Su, SC Kestin (2000) Effects of age and stocking density on leg weakness in broiler chickens. Poultry Science 79(6): 864-870.

25. SC Kestin, G Su, P Sorensen (1999) Different commercial broiler crosses have different susceptibilities to leg weakness. Poultry Science 78(8): 1085-1090.

26. JB Kjaer, G Su, BL Nielsen, P Sorensen (2006) Foot pad dermatitis and hock burn in broiler chickens and degree of inheritance. Poultry Science 85(8): 1342-1348.

27. De Baere, KJ Zoons (2004) Welzijn bij vleeskuikens. Pluimvee Nr. 37.

28. De Baere, KJ Zoons (2003) Strooiselkwaliteit bij vleeskuikens: een belangrijk aandachtspunt. Pluimvee Nr. 36.

29. Aydin, AC Bahr, A Pluk, T Leroy, Berckmans D (2013) Automatic identification of activity and spatial use of broiler chickens with different gait scores. Transactions of the Asabe 56:1123-1132.

30. MS Dawkins, HJ Lee, CD Waitt, SJ Roberts (2009) Optical flow patterns in broiler chicken flocks as automated measures of behavior and gait. Appl Animal Behav Sci 119(3-4): 203-209.
31. SC Kestin, TG Knowles, AE Tinch, NG Gregory (1992) Prevalence of leg weakness in broiler chickens and its relationship with genotype. Vet Record 131(9): 190-194.

32. SA Corr, CC Mccorquodale, MJ Gentle (1998) Gait Analysis of Poultry. Research in Veterinary Science 65(3): 233-238.

33. SA Corr, CC Mccorquodale, MJ Gentle D Bennett (2003) The effect of morphology on walking ability in the modern broiler: A gait analysis study. Animal Welfare 12(2): 159-171.

34. CA Weeks, TG Knowles, RG Gordon, AE Kerr, ST Peyton et al. (2002) New Method for Objectively Assessing Lameness in Broiler Chickens. Veterinary Record 151(25): 762-764.

35. SA Corr, CC Mccorquodale, MJ Gentle D Bennett (2007) Evaluation of Ground Reaction Forces Produced by Chickens Walking on a Force Plate. American Journal of Veterinary Research 64(1): 76-82.

36. Aydin A, Cangar O, Eren Ozcan S, Bahr C, Berckmans D (2010) Application of a fully automatic analysis tool to assess the activity of broiler chickens with different gait scores. Computers and Electronics in Agriculture 73(2): 795-802.

37. Aydin, AC Bahr, D Berckmans (2015) Automatic classification of measures of lying to assess the lameness of broilers. Animal Welfare 24(3): 335-343.

38. Bessei W (2006) Welfare of broilers: A review. Worlds Poultry Sci J 62(3): 455-466

39. Cangar, OS Cardinaels, N Everaert, B De Keteleare, C Bahr et al. (2009) A study on the cause and effect of lameness on broiler chickens. In Proc Joint Intl Agric Conf: Precision Livestock Farming.

40. Cook ME (2000) Skeletal deformities and their causes: Introduction. Poultry Sci 79(7): 982-984.

41. Cordeiro AFS, IA Nääs, DD Salgado (2009) Field evaluation of broiler gait score using different sampling methods. Braz J Poultry Sci 11(3): 149154.

42. MS Dawkins, R Cain, SJ Roberts (2012) Optical flow, flock behaviour and chicken welfare. Animal Behaviour 84(1): 219-223.

43. JP Garner, C Falcone, P Wakenell, M Martın, JA Mench (2002) Reliability and validity of a modified gait scoring system and its use in assessing tibia dyschondroplasia in broilers. British Poultry Science 43(3): 355363.

44. T Grandin (2007) Poultry slaughter plant and farm audit: critical control points for bird welfare. Information.

45. HH Kristensen, JM Aerts, T Leroy, CM Wathes, D Berckmans (2006) Modelling the dynamic activity of broiler chickens in response to stepwise changes in light intensity. Appl Animal Behav Sci 101(1-2): 125-143.

46. Rushen, JN Chapinal, AM Passille, (2012) Automated monitoring of behavioral-based animal welfare indicators. Animal Welfare 21: 339350.

47. KS Vestergaard, GS Sanotra (1999) Relationships between leg disorders and changes in the behaviour of broiler chickens. Vet Record 144(8): 205-209.

48. Akbas YS, Yalcin S, Özkan, Kırkpınar F, Takma Ç et al. (2009) Heritability estimates of tibial dyschondroplasia, valgus-varus, foot-pad dermatitis and hock burn in broiler. Arch Geflügelk 73(1): 1-6.

49. W Bessei (2006) Welfare of Broilers: A Review. Worlds Poultry Science Journal 62(3): 455-466

50. G Su, P Sørensen, SC Kestin (1999) Meal feeding is more effective than early feed restriction at reducing the prevalence of leg weakness in broiler chickens. Poultry Science 78(7): 949-955.

51. CA Weeks, TD Danburry, HC Davies, P Hunt, SC Kestin (2000) The behaviour of broiler chickens and its modifications by lameness. Applied Animal Behaviour Science 67(1-2): 111-125. 